\title{
IdeAs
}

Idées d'Amériques

$5 \mid 2015$

Crise ou transformations du monde du travail dans les

Amériques

\section{Crise ou transformação do mundo dos negócios nas Américas?}

\section{Donna Kesselman}

\section{OpenEdition}

\section{Journals}

Edição electrónica

URL: https://journals.openedition.org/ideas/4722

DOI: $10.4000 /$ ideas.4722

ISSN: 1950-5701

\section{Este artigo é uma tradução de:}

Crise ou transformations du monde du travail dans les Amériques ? - URL : https:// journals.openedition.org/ideas/1022 [fr]

Outra(s) tradução(ões) deste artigo:

Transformations in the labor market in the Americas - or is it crisis? - URL : https:// journals.openedition.org/ideas/3073 [en]

¿Crisis o transformación del mundo laboral en las Américas? - URL : https://journals.openedition.org/ ideas/3079 [es]

\section{Editora}

Institut des Amériques

\section{Refêrencia eletrónica}

Donna Kesselman, «Crise ou transformação do mundo dos negócios nas Américas?», IdeAs [Online], 5 | 2015, posto online no dia 10 dezembro 2018, consultado o 20 outubro 2022. URL: http:// journals.openedition.org/ideas/4722 ; DOl: https://doi.org/10.4000/ideas.4722

Este documento foi criado de forma automática no dia 20 outubro 2022

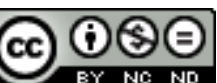

Creative Commons - Atribuição-NãoComercial-SemDerivações 4.0 Internacional - CC BY-NC-ND 4.0 https://creativecommons.org/licenses/by-nc-nd/4.0/ 


\title{
Crise ou transformação do mundo dos negócios nas Américas?
}

\author{
Donna Kesselman
}

1 Podemos falar de uma crise dos negócios nas Américas? Se a resposta é positiva, em que sentidon a crise é própria a este hemisfério? Como ela se espalha do Norte ao Sul e em cada país? Ou trata-se de apreender as configurações emergentes que caracterizam a globalização do mercado de trabalho do século XXI?

2 Esta é a questão que este número da IdeAs aborda, na sequência do número anterior consagrado às "Crises e efeitos da crise nas Américas", tratando aqui, particularmente, dos fenômenos ligados ao mundo dos negócios.

3 Tornou-se costumeiro apontar o dedo para a crise dos negócios que atinge os países industrializados nos últimos anos. A globalização financeira e as inovações técnicas e tecnológicas se combinam para derrubar tanto as fronteiras do comércio quanto da informação, e neste contexto se elaboram as políticas públicas neoliberais que minam as instituições históricas de regulamentação e de redistribuição social. A Great Recession de 2008, no que se refere ao mercado de trabalho e de empregos, apenas acelerou o processo já em andamento. Essa constatação, de ordem geral, merece ser complementada por algumas precisões.

4 A globalização, longe de ser homogênea, é tecida pela padronização e acima de tudo pela diferenciação (Azaïs C., 2010). Trata-se de um processo que não é uniforme, globalizing world labor market, do qual é preciso apreciar as particularidades nacionais, mas também outras escalas institucionais, sem esquecer as interações entre entidades sociais múltiplas (Kesselman D., 2010a; Giraud O., 2012). No que diz respeito ao trabalho, a diferenciação vem, de um lado, das resistências coletivas e individuais contra as pressões vindas das companhias transnacionais, que são cada vez mais flexíveis e de baixo custo de trabalho. Elas se expressam através dos movimentos sociais para a defesa do transporte público, da saúde e da educação num país tão dinâmico quanto o Brasil, ou através da criação de direitos sociais num país tão improvável quanto os Estados Unidos, onde alguns Estados federais agora exigem que as empresas pela primeira vez, vindo dos poderes públicos - atribuam aos funcionários uma licença 
remunerada (Thevenard E., 2015). Por outro lado, dando destaque às pressões de interesses locais, a flexibilidade também promove a diferenciação.

5 Certamente, do Sul ao Norte das Américas, existem realidades comparáveis, senão comuns: na edição anterior da IdeAs, Laurence Whitehead oferece uma série de fatores contextuais que legitima a ideia de uma especificidade de experiências para o que pode ser chamado de "Novo Mundo" (L. Whitehead, 2013). Os países da América Latina compartilham o fato de pertencer aos chamados países do "Sul" - Global South - um conceito ligado ao desenvolvimento do capitalismo. A designação, mais recente dos antigos "países subdesenvolvidos" ou de "terceiro mundo", refere-se às economias nacionais que não têm acesso direto ao mercado mundial. Anteriormente dominados ou colonizados pelos países desenvolvidos, eles ficaram na dependência da prosperidade mercantil e logo capitalista, devido à exploração e ao deslocamento de suas próprias riquezas para alimentar os países do Norte. Alguns são considerados hoje, segundo a linguagem politicamente correta, de países em desenvolvimento, e outros de países emergentes. Embora o significado desta última categoria esteja evoluindo rapidamente (P. Salama, 2014), a conotação do termo leva à confusão.

6 Esta última apelação, semelhante daquela cunhada a partir de 1960, a de "países em via de desenvolvimento", implica a existência de uma trajetória histórica linear que se encontraria na continuação daquela dos países do Norte, com sua própria revolução industrial e pós-industrial. Porém, essa concepção de um padrão suave do crescimento capitalista das democracias ocidentais tradicionais não coincide com a mudança de divisão internacional do trabalho. Além disso, os ambientes sócio-políticos próprios de cada país e as tensões que caracterizam o mercado global excluem qualquer visão simplificada, se não glorificada, de uma reprodução da história econômica.

7 A crise de 2008 teria vindo para confirmar a heterogeneidade das economias latinoamericanas. Conforme demonstrou Carlos Quenan, esta "realidade de trajetórias econômicas diversificadas" se aplica inclusive a países que em vários pontos podem ser aproximados, como o México e o Brasil. Vários fatores se combinaram neste último país para mitigar o impacto da crise, enquanto no México as consequências têm sido particularmente "violentas para a economia e para a população". Cada um dos países que dependem principalmente das receitas de exportação de petróleo reagiu de forma diferente frente à crise (Quenan C., 2013).

8 Estas reações poderiam ser explicadas pela existência de diferentes modelos nacionais. Existiriam até mesmo "variedades do capitalismo" (P. Hall e D. Soskice, 2001) específicas para a América Latina, articuladas entre dois polos formados pelos dois países que têm as maiores economias (Bizberg I., 2012; Théret B., 2002; Marques Pereira-J. e B. Théret, 2004) e que se distinguem particularmente no campo do trabalho. Segundo Bizberg, o Brasil pode ser qualificado de "State-led/onward oriented", em que o Estado desempenha um papel central na orientação da atividade econômica para o mercado interno, reforçando desta forma as bases para a integração ativa no mercado mundial. 0 artigo de Marcia Leite e Carlos Salas parece dar crédito a essa hipótese. Este estudo sobre a mudança dos negócios dá conta de uma redução das desigualdades, o que permitiu um melhor acesso dos pobres aos empregos mais qualificados. É uma tendência crescente, apesar do período de crise, e que se inscreve no modelo de desenvolvimento brasileiro. No outro polo e na extremidade oposta encarnada pelo México, o Estado ocupa apenas um lugar subsidiário de articulação da estrutura produtiva que, acima de tudo, se dirige ao exterior. Ele restringe a sua ação para a 
regulação e promoção do capital nacional através da intervenção contracíclica, delineando o que podemos chamar de "State regulated/externally-oriented capitalism". Esta percepção coincide com a de Élodie Segal, que caracteriza a sociedade mexicana como sendo "desfigurada pela desigualdade". A análise faz parte de um modelo de produção que, em nome da modernização do país, se orienta conforme as necessidades de financiamento e do cliente-mandatário. As pressões internas daí resultantes levam à desregulamentação, à individualização e - para a população mais frágil - à redução dos direitos sociais dos trabalhadores. É realmente o caso do México, onde o salário mínimo é um dos mais baixos da América Latina.

Outros países, como o Chile, conhecem as características dos dois modelos (Bizberg I., 2012). E é também nesses termos que, aqui, Guillermo Wormald e Maria Paz Trebilcock qualificam este país. A análise da relação entre o trabalho e a coesão social em áreas urbanas no Chile destaca o surgimento de uma "nova sociedade de mercado" que iria perturbar as relações antigas, impondo-se cada vez mais como um mecanismo para coordenar as oportunidades de acesso ao trabalho. Até que ponto o trabalho continuará a servir de vetor de criação de um espaço de encontro, de desenvolvimento social e de cidadania? Ao passo que, no final do século passado, a América Latina foi apresentada como um possível "laboratório social" do futuro do trabalho dos países do Norte, uma posição posteriormente tomada por Beck através da ideia de "brasilianização do Ocidente" (Beck Ü., 2000), esta experiência chilena verifica, aos nossos olhos, a hipótese que desenvolvemos neste número: ou seja, a ideia de que práticas atuais nos EUA, no que diz respeito à articulação do trabalho e aos benefícios sociais a partir do mercado (market based), poderiam mudar o rumo do experimento (Kesselman D., 2010b).

Podemos assim evidenciar uma diferenciação centrada na globalização entre e dentro das economias e sociedades, especialmente no que diz respeito aos mercados de trabalho e de emprego. As situações nacionais não são facilmente comparáveis, por causa das especificidades históricas das construções de cada Estado social e também de um sistema de relações de profissionais. Por exemplo, o caráter minimalista e fragmentado das instituições de regulamentação social nos Estados Unidos resulta das grandes diferenças de uma região para outra, de uma empresa para outra, nas características da relação do emprego (relação de trabalho). Todo o sistema está bem afastado do sistema de seu vizinho canadense, muito mais protetor (P.-A. Lapointe, 2013; D. Kesselman, 2007). Para os países do Sul, temos de levar em conta tanto a história sociopolítica quanto as diferenças no grau de desenvolvimento e as estratégias de desenvolvimento.

Algumas contribuições deste dossiê se interessam pelas relações industriais e pelas lutas coletivas que têm como meta, em seu contexto nacional, atenuar as consequências da globalização neoliberal. Apesar de seu enfraquecimento, o contra-poder do sindicalismo não disse sua última palavra.

12 As fábricas de confecção representam um dos principais setores que registraram um aumento do emprego formal na Guatemala, especialmente para as mulheres, num país onde a grande maioria da força de trabalho é objeto de atividades informais. Mas nesses maquilas encontramos as piores condições de trabalho e muita insegurança, com práticas antisindicais ferozes. Os trabalhadores não baixam a cabeça para os obstáculos e constrangimentos diários exercidos contra o exercício dos direitos sindicais, como nos revela Quentin Delpech, a partir de pesquisas de campo. 
13 A Venezuela é um caso excepcional. Thomas Posado analisa, a partir de um olhar de dentro, o movimento sindical que teve um papel fundamental nas transformações que ocorreram desde o advento do regime de Chávez. Este poder, que reivindica a participação popular assim como uma política de resistência às injunções das potências econômicas e financeiras globais, afetou o posicionamento das organizações trabalhistas, que foram forjadas no passado, e favoreceu a renovação do sindicalismo no país.

14 A IdeAs também apresenta, neste número, uma análise comparativa do sindicalismo norte-americano. Como explicar a existência, nos EUA, de uma taxa de sindicalização entre as mais baixas do mundo ocidental, enquanto ela está entre as maiores no Canadá? Paul-André Lapointe, especialista em relações industriais na Universidade Laval, em Quebec, observa numa entrevista esta situação aparentemente paradoxal, dadas as semelhanças socioeconômicas e a história comum que aproximou os movimentos de trabalhadores dos dois países (aludimos à implementação de uma legislação de gestão de relacionamento profissional na indústria e ao estabelecimento das chamadas Uniões Internacionais, que são organizações presentes tanto nos EUA como no Canadá). 0 artigo traça esta evolução cruzada e logo, a partir da década de 1960, cada vez mais divergente, dando destaque aos desafios enfrentados pelos trabalhadores e a suas organizações atuais. $O$ prisma dos direitos sindicais também oferece uma visão geral da cultura política e social, extrremamente diversa em cada uma das províncias canadenses.

Estas experiências nacionais de crescimento econômico e de defesa dos interesses sociais coletivos levam à diferenciação em termos de igualdade social. Qualquer avaliação da situação e do trabalho, do Sul para o Norte, e até dentro das sociedades particulares, deve ir além das estatísticas macroeconômicas. As taxas de crescimento elevadas e a extensão do trabalho assalariado em toda a América Latina, apesar da crise, despertam os sohnos de seus vizinhos do Norte. Portanto, tudo isso não levou à construção de uma relação de trabalho assalariado acompanhada de benefícios sociais no nível historicamente alcançado por aqueles no Norte; e observamos, também nesta região, a proliferação de empregos precários (Giglia A., 2014; C. Rosenfield, 2010).

Além disso, a informalidade não diminuiu no subcontinente, e na verdade mudou seu rosto e sua natureza (Azaïs C. e M. Lehalleur, 2014).

Guillermo Wormald e Maria Paz Trebilcock ilustram a complexidade do fenômeno no Chile: o emprego formal, sob a forma do trabalho assalariado, cresce para os homens como as mulheres, de todas as idades e em todos os níveis de renda e além disso, sob a forma de CDI (contrato permanente). Porém, esses contratos, com exceção do último decil (os $10 \%$ dos funcionários mais bem pagos) não são tão protetores quanto os contratos que conheceram, em particular, os funcionários europeus.

18 Assim, no momento da globalização neoliberal, se destaca uma interrogação quanto às perspectivas sociais existentes, mesmo em economias prometidas a um desenvolvimento sem precedentes, enquanto o quadro de redistribuição social mais amplo do Norte é condenado a se encolher inexoravelmente.

19 A história, no entanto, não é, obviamente, escrita com antecedência. As contribuições desta edição da IdeAs nos permitem voltar a fazer, em termos mais atuais, a pergunta de partida: há uma crise de trabalho ou nos encontramos na presença de novas configurações, qu seriam características da globalização e caracterizariam o novo 
século (D’Amours M. et al., 2015)? A resposta vai depender não apenas dos atores, mas também da saúde do sistema.

Uma nova fase de recuperação foi anunciada após a crise global desencadeada pelo colapso da bolsa americana de 2008. No início de 2014, o jornal francês Le Monde declarou: "O FMI prevê uma 'recuperação' mais forte e mais ampla" (Guélaud C., 2014). Posteriormente, o FMI voltou atrás: na véspera do $45^{\circ}$ Fórum Econômico Mundial em Davos, em janeiro de 2015, o FMI reviu as suas previsões para baixo. Deixa-se antever o enfraquecimento do investimento e do crescimento potencial na maior parte dos "grandes países"; a retomada na área do euro e no Japão será mais lenta do que era esperado. Quanto aos países emergentes e em desenvolvimento, incluindo os BRICS, cujo dinamismo foi celebrado no início dos anos 2000, eles passam por um período difícil, particularmente a África Subsaariana e a América Latina. Isto é devido, entre outras coisas, à queda dos preços das comodidades. Apenas a economia dos EUA tem projeções revisadas para cima (FMI, 2015).

21 Volante de condução da economia mundial, a economia dos EUA, que se dinamiza, deveria ser favorável ao mercado de trabalho, começando com o mercado de seu próprio país. No entanto, não é o que Donna Kesselman escreve em seu artigo: segundo ela, o modelo de emprego, o American Job Machine, passa por uma crise estrutural. Olivier Frayssé aumenta os riscos a longo prazo: o virtual desaparecimento do regime de pensões nos Estados Unidos tem implicações que vão muito além do destino deste benefício social, uma vez que eles são indicativos do eclipse dos próprios fundamentos do sonho americano. Finalmente, Christian Azaïs propõe uma reflexão teórica sobre a transformação do trabalho num mundo globalizado: é uma ampliação do processo já em andamento ou uma crise acompanhada de uma mudança de natureza?

Cabe às leitoras e aos leitores da IdeAs julgar de tudo isso. Este panorama de pesquisas de uma grande riqueza, realizado por dezesseis autores que trabalham em sete países das Américas, oferece perspectivas de análises múltiplas - sobre a evolução e a emergência de mercados de trabalho e de emprego, sobre as características flutuantes desses fenômenos, sobre o papel dos antigos e novos autores que são indicadores do futuro das sociedades e que alimentarão, nós esperamos, suas reflexões.

\section{BIBLIOGRAFIA}

Azaïs, Christian, « Amérique du Sud : Travail ; Syndicalisme ", in Michel Bertrand, Antoine Coppolani, Isabelle Vagnoux, Jean-Michel Blanquer (dir.), Dictionnaire des Amériques, Paris, Laffont Collection Bouquins, à paraître en 2016.

Azaïs, Christian (dir), « Introduction », Labour and Employment in a Globalizing World : Autonomy, collectives and political dilemmas, Brussels, Peter Lang. 2010.

Azaïs Christian et Pepin-Lehalleur Marielle (dir.), Modes de gouvernance dans quatre métropoles latino-américaines (Buenos Aires, Caracas, Mexico et São Paulo) : entre logiques institutionnelles et acteurs, Bruxelles, P.I.E. Peter Lang Ed., 2014. 
Beck, Ülrich, The Brave New World of Work, Oxford, Polity Press, 2000.

Bizberg, Ilan, « Types of capitalism in Latin America », Revue Interventions économiques, $\mathrm{n}^{\circ}$ 47, 2012, p. 1-26, http://interventionseconomiques.revues.org/1772.

D’Amours, Martine, Soussi, Sid Ahmed, Tremblay, Diane-Gabrielle (dir.), Repenser le travail : Des concepts nouveaux pour des réalités transformées, Québec, Presses de l'Université de Québec, 2015.

FMI, Fonds monétaire international, « Les prévisions de croissance mondiale sont révisées en baisse malgré le repli des prix du pétrole et l'accélération de la croissance américaine », Bulletin du FMI, 20 janvier 2015, http://www.imf.org/external/French/pubs/ft/survey/so/2015/ NEW012015AF.html, consulté le 2 avril 2015.

Giglia, Angela, « Trabajo precario y redes de solidaridad. El caso de los gasolineros en la ciudad de México ", in Angela Giglia et Adelina Miranda (coords), Precariedad urbana y lazos sociales. Una perspectiva comparativa entre México e Italia, México, UAM-Juan Pablos editores, p. 109-137, 2014.

Giraud, Olivier, « L'analyse scalaire des régimes d'action publique en Europe : l'apport méthodologique des comparaisons internationales ", Revue internationale de politique comparée, vol. 19, n², p. 15-36, 2012.

Guélaud, Claire, "Le FMI entrevoit une reprise 'plus forte et plus large' », Le Monde, 8 avril 2014, https://www.lemonde.fr/economie/article/2014/04/08/le-fmi-entrevoit-une-reprise-plus-forteet-plus-large_4397717_3234.html\#ZAXV65cyXjha3dYj.99, consulté le 5 mars 2015.

Hall, Per A., Soskice, David, Varieties of Capitalism, Oxford University Press, 2001.

Kesselman, Donna, « Travail et salariat aux États-Unis : Quels droits, quelles perspectives?», Revue Française d'Etudes Américaines, n 111, 2007, p. 6-26.

Kesselman, Donna, « A Globalizing labour and employment market » (Postface), in Christian Azaïs (Dir.), Labour and Employment in a Globalizing World: Autonomy, collectives and political dilemmas, Brussels, Peter Lang. 2010a, p. 267-273.

Kesselman, Donna, « Trabalho precário e precarização institucional nos Estados-Unidos », («Travail précaire et précarisation institutionnelle aux États-Unis »), Sociologias, vol. 12, $n^{\circ} 25$, novembre/décembre, 2010b, p. 66-100.

Lapointe, Paul-André (Dir.), La qualité du travail et de l'emploi au Québec. Données empiriques et cadres conceptuels, Québec, Presses de l'Université Laval, 2013.

Marques Pereira, Jaime et Théret, Bruno, « Mediaciones institucionales de regulación social y dinámicas macroeconómicas : los casos de Brasil y México » in Carlos Alba et Ilán Bizberg (Dir.), Democracia y Globalización en México y Brasil, México, El Colegio de México, 2004.

Quenan, Carlos, « América latina frente a la crisis económica internacional: buena resistencia global y diversidad de situaciones nacionales ", IdeAs, $\mathrm{n}^{\circ}$ 4, Automne 2013, http:// ideas.revues.org/780.

Rosenfield, Cinara (dir), « Trabalho, emprego e pracarização social », Sociologias, vol n 12, $n^{\circ} 25$, novembre/décembre 2010.

Salama, Pierre, Des pays toujours émergents ?, Paris, La Documentation Française, 2014.

Théret, Bruno, Protection Sociale et Fédéralisme. L'Europe dans le miroir de l'Amérique du Nord, Montréal, Presse de l'Université de Montréal - Peter Lang, 2002. 
Thevenard, Evelyn, « Paid Family Leave as Public Policy : A View from the States », in Gérard Gomez et Donna Kesselman (Dir.), Les femmes au travail dans les Amériques, Aix-en-Provence, Presses Universitaires de Provence (PUP), à paraître en 2015.

Whitehead, Laurence, " 'Crisis' in the Americas : Is there a Regionally Distinctive Kind ? ", IdeAs, $\mathrm{n}^{\circ}$ 4, Automne 2013, http://ideas.revues.org/611.

\section{AUTOR \\ DONNA KESSELMAN}

Donna Kesselman est Professeure des Universités à l'Université Paris-Est Créteil. Elle publie largement sur les questions du travail, de l'emploi et des relations professionnelles, en proposant une perspective comparative, (France, États-Unis, Brésil, Canada). Elle est co-rédactrice d'un recueil d'articles publié aux Presses Universitaires de Provence, articles issus des communications qui ont été faites lors du Congrès de l'IDA de 2013 «Les Femmes dans les Amériques ", et plus particulièrement de l'axe thématique « Les femmes et le travail dans les Amériques ». Elle a co-rédigé des études de la DARES sur les relations professionnelles. Elle est au bureau du RT 18 de l'Association Française de Sociologie traitant des relations professionnelles. 